Elsevier Editorial System(tm) for Journal of Affective Disorders

Manuscript Draft

Manuscript Number: JAD-D-11-00955R1

Title: Effectiveness of a universal school-based programme for preventing depression in Chinese adolescents: A quasi-experimental pilot study

Article Type: Research Paper

Keywords: Adolescent depression; universal prevention programme; school-based intervention; cognitive-behavioural approach; Hong Kong.

Corresponding Author: Dr. Paul Wai-Ching Wong, D.Psyc.(Clinical)

Corresponding Author's Institution: The University of Hong Kong, Dept of Social Work and Social Administration, Faculty of Social Sciences, and HKJC Centre for Suicide Research and Prevention

First Author: Paul Wai-Ching Wong, D.Psyc.(Clinical)

Order of Authors: Paul Wai-Ching Wong, D.Psyc.(Clinical); King-Wa Fu, PhD; Kim Yin Kwan Chan; Wincy Siu Chuk Chan; Patricia Ming Yan Liu; Yik-Wa Law; Paul Siu Fai Yip, PhD

Abstract: Background: Evidence of the effectiveness, rather than efficacy, of universal school-based programmes for preventing depression among adolescents is limited. This study examined the effectiveness of a universal depression prevention programme, "The Little Prince is Depressed" (LPD), which adopted the cognitive-behavioural model and aimed to reduce depressive symptoms and enhance protective factors of depression among secondary school students in Hong Kong. Methods: A quasi-experimental design was adopted for this pilot study. Thirteen classes were assigned to the intervention or control conditions according to the deliberation of the programme administrator of the four participating schools. Implementation was carried out in two phases, with a professionalled first phase and teacher-led programme second phase. LPD consisted of a 12-week school-based face-to-face programme with psycho-educational lessons and homework assignments.

Results: Students completed the programme generally showed positive development in help-seeking attitudes and self-esteem. For students who had more depressive symptoms at pre-assessment, the programme was found to be significant in enhancing cognitive-restructuring skills and supportseeking behaviours. The programme was not, however, found to be statistically significant in reducing depressive symptoms of the participants over the study period.

Limitations: A small sample size, a high attrition rate, and a short follow-up time frame.

Conclusions: The LPD programme was successful in building resilience of the students in general and enhancing the cognitive-behavioural skills of students with depressive symptoms. While we did not find sufficient evidence for concluding that the LPD was effective in reducing depressive symptoms, we believe that these results highlight the challenges of implementing evidence-based practices generated from highly controlled environments in real-life settings. 
Contributors: Paul W.C. Wong, King-Wa Fu, Kim Y.K. Chan, Wincy S.C. Chan and Patricia M.Y. Liu wrote the proposal. Yik-Wa Law and Paul S.F. Yip obtained funding for the research project. All authors contributed equally to the literature searches, statistical analyses, and the draft of the manuscript. All authors contributed to and have approved the final manuscript. 


\title{
Effectiveness of a universal school-based programme for preventing depression in Chinese adolescents: A quasi-experimental pilot study
}

\author{
Authors: \\ Paul W.C. Wong, D.Psyc. (Clinical), Department of Social Work and Social Administration, \\ Faculty of Social Sciences, University of Hong Kong, and HKJC Centre for Suicide Research \\ and Prevention, the University of Hong Kong, Pokfulam, Hong Kong; ${ }^{1}$ \\ King-Wa Fu, Journalism and Media Studies Centre, The University of Hong Kong, and HKJC \\ Centre for Suicide Research and Prevention, the University of Hong Kong, Pokfulam, Hong \\ Kong;
}

Kim Y.K. Chan, Department of Social Work and Social Administration, Faculty of Social Sciences, the University of Hong Kong, Pokfulam, Hong Kong;

Wincy S.C. Chan, Faculty of Education, the University of Hong Kong, and HKJC Centre for Suicide Research and Prevention, the University of Hong Kong, Pokfulam, Hong Kong;

Patricia M.Y. Liu, Department of Social Sciences, Hong Kong Institute of Education, Hong Kong SAR, Tai Po, Hong Kong;

Yik-Wa Law, Department of Social Work and Social Administration, Faculty of Social Sciences, University of Hong Kong, and HKJC Centre for Suicide Research and Prevention, the University of Hong Kong, Pofulam, Hong Kong;

and

Paul, S.F. Yip Ph.D., Department of Social Work and Social Administration, Faculty of Social Sciences, University of Hong Kong, and HKJC Centre for Suicide Research and Prevention, the University of Hong Kong, Pokfulam, Hong Kong.

\footnotetext{
${ }^{1}$ Corresponding Author:

Paul W.C. Wong, D.Psyc. (Clinical), Department of Social Work and Social Administration, Faculty of Social Sciences, University of Hong Kong, and HKJC Centre for Suicide Research and Prevention, the University of Hong Kong, Pokfulam, Hong Kong

Address:

Telephone:

Fax:

Email:

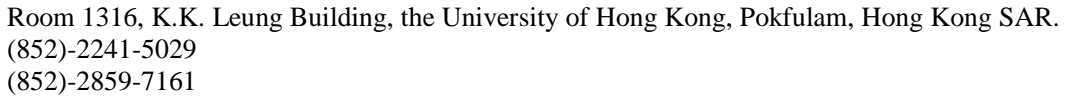




\begin{abstract}
:
Background: Evidence of the effectiveness, rather than efficacy, of universal school-based programmes for preventing depression among adolescents is limited. This study examined the effectiveness of a universal depression prevention programme, "The Little Prince is Depressed" (LPD), which adopted the cognitive-behavioural model and aimed to reduce depressive symptoms and enhance protective factors of depression among secondary school students in Hong Kong.

Methods: A quasi-experimental design was adopted for this pilot study. Thirteen classes were assigned to the intervention or control conditions according to the deliberation of the programme administrator of the four participating schools. Implementation was carried out in two phases, with a professional-led first phase and teacher-led programme second phase. LPD consisted of a 12-week school-based face-to-face programme with psycho-educational lessons and homework assignments.

Results: Students completed the programme generally showed positive development in helpseeking attitudes and self-esteem. For students who had more depressive symptoms at preassessment, the programme was found to be significant in enhancing cognitive-restructuring skills and support-seeking behaviours. The programme was not, however, found to be statistically significant in reducing depressive symptoms of the participants over the study period. Limitations: A small sample size, a high attrition rate, and a short follow-up time frame.

Conclusions: The LPD programme was successful in building resilience of the students in general and enhancing the cognitive-behavioural skills of students with depressive symptoms. While we did not find sufficient evidence for concluding that the LPD was effective in reducing depressive symptoms, we believe that these results highlight the challenges of implementing evidence-based practices generated from highly controlled environments in real-life settings.
\end{abstract}

\title{
Keywords:
}

Adolescent depression; universal prevention programme; school-based intervention; cognitivebehavioural approach; Hong Kong; China. 


\section{Introduction}

Psychological autopsy studies have consistently found that major depression is one of the most robust risk factors for youth suicide (Bursztein \& Apter, 2009). Epidemiological studies have shown that unipolar depressive disorders often begin in adolescence and affect about 3\%$8 \%$ of adolescents in the US (Garber, 2006), and that approximately $21 \%-28 \%$ of adolescents experience an episode of major depression by age 19 (Merry, McDowell, Hetrick, Bir, \& Muller, 2004). The youth prevalence rates of depressive symptoms and depressive disorders in Hong Kong have been estimated at about $9 \%$ and 1.3\%, respectively (Leung et al., 2008).

Depression among adolescents is associated with poor academic performance, social dysfunction, high-risk sexual behaviour, and poor physical health (Merry et al., 2004) and may continue into adulthood resulting in further occupational, financial, and social difficulties (Gladstone \& Beardslee, 2009). Taken together, these points make a strong case for prevention programmes in addressing the morbidity, or even mortality, associated with undiagnosed and untreated adolescent depression.

Three general approaches can be used to reduce the prevalence of adolescent depression: (a) universal (all members of the target population), (b) selective (a subgroup of the target population whose risk is deemed to be above average compared with the general population as the target population), and (c) indicated (individuals who display subclinical or clinical signs or symptoms of depression as the target population (Mrazek\& Haggerty, 1994)). Offord and colleagues (1998) commented that although selective and indicated programmes provide close personal contact and great potential efficacy, universal programs have the benefit of reducing stigma and implementing broad application; this benefit comes, however, at the cost of smaller individual effects and greater impersonality. Andrews, Szabo, and Burns (2002) also stated that 
although selective programmes may have larger effects for individual participants, universal programmes have multiple smaller effects on a larger number, which may in turn have an enormous effect on the larger society. The smaller effect sizes could also be explained by the number of extraneous variables, such as age and gender differences, length of sessions, characteristics of programme leaders, and initial levels of risk among participants (Horowitz et al., 2006; Merry et al., 2004). Thus, despite the smaller effects found in universal versus selective or indicated programmes, such universal, school-based prevention programmes for adolescent depression are still widely implemented (Spence \& Shortt, 2007).

According to a systematic review of school-based prevention and early intervention programs for youth depression implemented from 1998 to 2008 (Calear \& Christensen, 2010), $55 \%$ of 42 identified studies in the review were universal trials that included all students, $14 \%$ were selective trials, and $24 \%$ were indicated trials. Cognitive Behavioural Therapy (CBT) formed the basis of the majority of all identified studies. Of the 23 universal trials that included all participants regardless of symptom level, nine trials showed reductions in depressive symptoms at post-test, while 14 trials did not. The authors concluded that the universal programs that included all participants regardless of symptom level, displayed the lowest level of efficacy and effectiveness. However, tThey believed that the content and delivery style of the reviewed universal trials, however, may be the crucial factors affecting the outcomes of the studies rather than the universal approach itself.

A small number of studies have attempted to study the impact of the level of risk among participants as a confounding variable, because students who report higher levels of depressive symptoms at the first assessment may benefit much more than those with no or low levels of symptoms (Horowitz et al., 2006). Hence, analyses between students with high and low 
symptoms have been separated based on depression scores at the baseline evaluation time point (Cardemil, Reivich, Beevers, Seligman, \& James, 2007). These studies, however, have also produced mixed results. Some studies found clear benefit for both high and low symptom groups immediately after the interventions, whereas others found no effectiveness for either group. These studies did tend to show that the higher symptom groups benefited more than the lower symptom groups (Merry et al., 2004).

This paper reports the development, implementation, and evaluation of a universal, school-based pilot programme for preventing adolescent depression in Hong Kong. The development of the programme was the logical step in a locality where (a) a relatively small number of psychologists and psychiatrists arewere available (World Health Organization, 2005); compared with other developed cities, thus limiting the provision of selective and indicated prevention initiatives andpharmaco/psychological treatment of adolescents with depression interventions (World Health Organization, 2005); and (b) evidence-based prevention programmes for Chinese youth depression arewere scarce, as in other non-Western societies. One of the few available studies conducted among Chinese students and published in English was that of Yu and Seligman (2002), who adopted a school-based intervention programme (the Penn Optimism Program, or POP) based in the US and implemented it among Chinese children in Beijing. Their results demonstrated that the Chinese version of the POP significantly prevented depressive symptoms, and the effect persisted for at least 6 months after the intervention.

The present study evaluated the effectiveness of a two-phase universal programme, the "Little Prince is Depressed" (LPD), based on the cognitive-behavioural model, which aimed to reduce depressive symptoms and enhance student knowledge of depression and life skills such as goal setting, cognitive restructuring, communication, problem solving, conflict resolution, and 
anger management. This approach to youth depression is consistent with diathesis-stress models of depression that regard the cognitive and behavioural characteristics of an individual as influencing the impact of adverse life events, as well as having a direct influence upon the development of depression (Cheng \& Chan, 2007; Mezulis, Hyde, \& Abramson, 2006). In this study, we specifically primarily addressed the effectiveness of the present pilot programme in reducing depressive symptoms among the subject group, especially the high-symptom students, in relation to the wait-list control group. We secondarilyadditionally addressed the effectiveness in enhancing protective factors of depression among the subject group. The hypotheses we examined were that, (1) compared with adolescents who did not receive the programme (i.e., the wait-list controls), those who participated in the universal prevention programme would show statistical significantly lower levels of depressive symptoms and stress level at the postintervention measurement time point; and (2) compared with adolescents who did not receive the programme (i.e., the wait-list controls), those who participated in the universal prevention programme would show statistical significantly higher levels of help-seeking behaviours, selfesteem, social support, problem-solving and coping behaviours at the post-intervention measurement time pointas well as greater levels of a number of protective factors (e.g., self esteem, coping skills, and problem-solving skills) at the end of the study period.

\section{Methods}

\subsection{Design}

We adopted a quasi-experimental design with an intervention condition and a control condition for the study. Since the participating schools did not consent to selecting classes through randomisation, classes were assigned to the intervention or control condition according to the 
deliberations of the school principals or the responsible school personnel of the participating schools. It was estimated that 260 subjects per condition (equivalent to about three schools) were required for results to be considered clinically significant assuming a power of 0.80 , a two-tailed alpha of 0.05 , and correlated pre-post measures. Unfortunately, because of limited funding, only two secondary schools per condition (four schools, designated Schools A, B, C, and D) participated in the study.

\subsection{Participants and recruitment}

A total of 13 classes from four schools participated. Two coeducational schools (Schools A and B) participated in the professional-led programme, consisting of three classes from School A and four from School B. The students were enrolled in Form 3 (equivalent to Year 9). The teacher-led programme involved Schools C and D, and consisted of three all-boy classes and two coeducational classes from School C, and one all-boy class from School D.

A total of 216 and 194 students aged 14-16 years participated in the professional-led and teacher-led programmes, respectively, and completed the pre-test questionnaires about one week before the first session (Figure 1). Each student was assigned an identification code (i.e., school number + class number + date of birth + gender) to ensure confidentiality. Classes in each school were then assigned to the intervention and wait-list control groups. Immediately upon completion of the programme, 172 post-test questionnaires were collected from the professionalled programme with 97 from the intervention group and 75 from the control group and 108 posttest questionnaires were collected from the teacher-led programme with 63 from the intervention group and 45 from the control group.

Table 1 shows the characteristics of the students at the pre-test and post-test evaluations of the programme. The attrition rates for the professional-led and teacher-led programmes were 
$20 \%$ and $44 \%$, respectively. For the professional-led programme, the attrition rates of the intervention and control conditions were $12 \%$ and $29 \%$ respectively. For the teacher-led programme, the attrition rates of the intervention and control conditions were both $44 \%$. Attrition was mainly the result of absenteeism during the administration of the post-test evaluation, unmatched identification codes between pre-test and post-test evaluations, and invalid questionnaires. Unmatched identification codes between pre-test and post-test evaluations were a result of difficulties with teachers administering the pseudo numbers used as identifiers and with students copying these numbers incorrectly. Invalid questionnaires, including sloppy filling or deliberate misfilling of information, were excluded from the analyses.

\subsection{Measurements}

Participants were assessed using validated scales on (a) levels of stress and depression experienced by participating adolescents as primary outcome measures, and (b) individual-level protective factors (i.e., self-esteem, perceived social support, coping styles, social problemsolving skills, and help-seeking patterns) for adolescent depression_as secondary outcome measures. Participants in the intervention and the wait-list control conditions were given the same pre-test and post-test questionnaire sets. Parental consent for study participation was sought a week prior to the pre-test. Participant information was collected anonymously, with date of birth used as an identifier for the post-test. We use gender to distinguish those students in the same class with the same date of birth. Probability of the combination of the same class with the same gender and date of birth is considered to be very small. Like previous studies (Naylor, Cowie, Walters, Talamelli, \& Dawkins, 2009; Shochet et al., 2001), only data from students who completed both assessments were included in the analyses.

\subsubsection{The Depression Anxiety Stress Scale.}


A subset consisting of only the depression and stress subscales (a total of seven items per

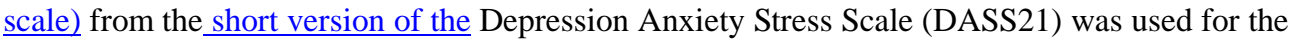
study. The factor structure of the Chinese version DASS, tested among Hong Kong Chinesespeaking adolescents with confirmatory factor analysis, had demonstrated that negative emotional syndromes of depression, anxiety, and stress were significantly discriminated (Taouk, Lovibond, \& Laube, 2001). Obtained scores are multiplied by two to allow comparison with the DASS normative data with higher scores indicating higher severity.

\subsubsection{Rosenberg Self-Esteem Scale.}

We used the Rosenberg Self-Esteem Scale (RSES), a 10 item Likert scale with answers on a four-point range, to measure the global self-esteem of the students, since it has shown high validity in_samples of children, adolescents, and adults (Bagley, Bolitho, \& Bertrand, 1997; Robins, Hendin, \& Trzesniewski, 2001). Higher scores indicate higher self-esteem. RSES has also been found to have high applicability for Chinese populations and has been used in many local studies (Yeung, 1998).

\subsubsection{The Multidimensional Scale of Perceived Social Support.}

The Chinese version, as validated by Chou $(2000 ; \alpha=.89)$, of the Multidimensional Scale of Perceived Social Support (MSPSS), as validated by Chou $(2000 ; \alpha=.89)$, was used to measure the adequacy of social support assessed subjectively by an individual (Zimet, Dahlem, Zimet, \& Farley, 1988). The scale has 12 item measured on a five-point scale with higher scores indicating higher levels of perceived social support.

\subsubsection{Brief COPE. The Brief COPE (Carver, 1997)}

A shortened version containing 28 items of the original COPE inventory (Carver, Scheier, \& Weintraub, 1989) was translated and back-translated into Chinese ensuring its equivalency to 
the original scale. Students were asked to indicate how often they used each strategy to respond to stress where items were scored 1 through 4 with two sets of total scores, one for usage of negative coping strategies and one for usage of positive coping with higher scores indicating use of more coping strategies by the students.

2.3.5. The Chinese Version of the Social Problem-Solving Inventory Revised.

The 25-item A short form of the Chinese Version of the Social Problem-Solving Inventory Revised (C-SPSI-R) was used. Positive subscale scores were aggregated with reversed scores of negative subscales to yield a final score where a higher score indicated better social problem solving ability. Siu and Shek (2005) showed that social problem-solving ability, involving different levels of activities (cognitive, affective, and behavioural), reduced the impact of life stress and helped children cope with academic stress.

\subsubsection{Help Seeking.}

We used the 10-item Attitudes Toward Seeking Professional Psychological Help: A Shortened Form (ATSPPH-SF) (Fischer \& Farina, 1995) to determine whether students would seek help from professionals, family members, friends, or teachers if they had a mental breakdown. Items are scored on a four-point Likert-type scale whereA higher score indicated a more positive attitude toward seeking help for psychological problems.

\subsection{Procedure}

We conducted this pilot study from 2006 to 2008 at four secondary schools in Hong Kong: Formatted: Indent: First line: 1.27 $\mathrm{cm}$

The study was implemented in two phases. In the first phase, during the 2006-2007 school year, the programme was facilitated by a professional team (two research social workers trained and supervised by an experienced clinical psychologist) and observed by teachers in the participating schools. In the second phase, during the 2007-2008 school year, the programme was facilitated 
by the teachers who had observed the first phase and was supervised by the research team.

Classroom instructions were facilitated bysupported with multimedia materials developed by the research team. In-Aadditionally, learning activities were designed to help students apply classroom knowledge to real-life contexts. A teacher handbook and a student workbook were developed to facilitate high quality delivery of the programme and student learning. These materials were uploaded onto the Internet to enhance accessibility byfor the teachers and students (http://csrp.hku.hk/qef). The study was approved by the Human Research Ethics Committee for Non-Clinical Faculties, The University of Hong Kong.

Letters were sent to potential schools with the help of the Hong Kong Education Bureau inviting interested school personnel to attend a 3-hour briefing session conducted by the research team on the mental health of secondary school students-conducted by the research team. The research design and potential risks of the programme were explained to the attendees. The project manager and the -research team further contacted interested schools. School visits for the participating schools were made to familiarize the school staff with the programme and the research team. The research team also conducted a one-day briefing session for all participating schools about a month prior to implementing the programme.

During the first phase of the implementation stage, the school teachers in the participating schools observed and assisted the research team in all 12 programme sessions as part of the teacher training package. Upon completing the first phase, the school teacher-observers received a half-day training session that aimed to answer theirany enquiries raised after observing the professional-led programme. In the second phase of the implementation stage, the trained school teachers conducted the programme, while the research team provided on-going consultations through-via telephone ealls-or e-mails. 


\subsection{Intervention}

The programme consisted of twelve 45-to-60-minute sessions, which took place

Formatted: No bullets or numbering

during regular school hours. The twelve sessions were disseminaconducted face-to-face to the

with students by the research team in the first phase and by the school teachers in the second phase. The sessions included topics covering the prevalence of and risks for depression and stress, the myths and facts about negative thought patterns, the identification of activating events and $\underline{\text { negative beliefs, and self-management skills such as problem solving, communication and }}$ interpersonal skills, conflict resolution, anger management, and positive coping. Details; such as the teaching materials and manuals of the programme can be found at http://csrp.edu.hk/qef. Each session was implemented using this sequence: introduction of the learning outcomes, psychoeducation lecturesing, mini-games/exercises, discussions, and conclusions.

\subsection{Statistical Analysis}

We followed Using the suggested way of analysing pretestpre-test-posttestpost-4 test designs (Bonate, 2000)., we regressed $t$ The log-transformed pesttestpost-test scores were $\underline{\text { linearly regressed on the intervention effect and controlled for covariates including pretestpre- }}$ test score, gender, and school. We adjusted within-class cluster correlation by correcting the standard error of the regression coefficients (Rogers, 1993). A mixed-effect model, another $n$ increasingly-common statistical approach to analysing cluster data, was not used for this study because of the small number of clusters, which were fewer than the suggested size of 15 per group (Hayes, 2009). We did not deploy ANCOVA because its routine in Stata does not provide the option to adjust for within-cluster correlation, which could have-inflated the estimation of 
standard error. The samples of the two intervention conditions (professional-led and teacher-led) were combined and represented by a dummy independent variable. $I$ where its interaction with the intervention effect $(2 \times 2)$ was entered into the model to test the effect between two conditions. The major reason of combining two into a larger sample is to boost the statistical power.

We conducted a subgroup analysis specifically for both the intervention and control group students whose pretestpre-test scores of depressive symptoms ranked above the $75^{\text {th }}$ percentile. Based on the suggested severity ratings of the DASS manual (Lovibond \& Lovibond, 1995), the cutoffcut-off range of scores effor moderate depression is 7 to 10 , as measured by DASS21 7-item depression sub-scale. In our baseline sample, the 75th percentile of their students' pre-test depression scores wasere 7. That is the and therefore, was the reason why the $75^{\text {th }}$ percentile was used as the euteffcut-off. We also tested the intervention-by-subgroup effect Formatted: Superscript

on the posttestpost-test scores with the same covariates and adjustment used for the main analysis.

We further used various t_-tests to investigate pre-existing differences in mean scores between the intervention and control groups,, but found no significant differences in gender distribution and in most of the pretest measurements between the intervention and control groups. The intervention group, however, did exhibit higher scores of depression ( $p<0.05)$ and stress ( $p$ $<0.05)$ than the control group. Stata 10.1 for Windows was the statistical tool used for all analyses.

\section{Results}

\subsection{Baseline data - Pre-intervention difference between groups}

$4 \quad$ Formatted: Bullets and Numbering 
T-tests found no significant differences in gender distribution and in most of the pretestpre-test measurements between the intervention and control groups. The intervention group, however, did exhibit higher scores effor depression $(\mathrm{p}<0.05)$ and stress $(\mathrm{p}<0.05)$ than the control group.

Moreover, wWe found no gender difference between those who completed both questionnaires and dropouts $(\mathrm{p}=0.189)$, whereasbut -those who completed both questionnaires had slightly higher pretestpre-test depression scores than those the dropouts $(\mathrm{p}<0.05)$.

\subsubsection{Differences Between Intervention and Control Groups}

Table 2 shows the mean item scores of the pretestpre-test and posttestpost-test for the intervention effect of the overall sample. Most outcome measures, including stress, depressive symptoms, social support, coping, and problem solving demonstrated no significant changes at the posttestpost-test, such that their beta coefficient values were not statistically different from zero ( $\mathrm{p}$ value is larger than 0.05$)$. Only the score for attitudes toward help seeking $(\mathrm{p}=0.002)$ and self-esteem $(\mathrm{p}=0.04)$ increased in the intervention group compared with the control group.

\subsubsection{Differences Between Students with High Depressive Symptoms in the} Intervention and Control Groups

Table 3 shows the results of the subgroup analysis. We found two variables, cognitive restructuring $(\mathrm{p}=0.03)$ and support seeking $(\mathrm{p}=0.02)$, to be statistically and significantly different between high depressive symptom students with high depressive symptoms -in the intervention and the control groups.

\section{Discussion}

In this study, we sought to provide empirical data by testing a universal, school-based
Formatted: Justified, Indent: First line: $1.27 \mathrm{~cm}$

Formatted: Justified

Formatted: Bullets and Numbering

Formatted: Bullets and Numbering

\section{Formatted: Justified}


programme for-in preventing depression among adolescents on (a) whether it could lower, compared with the control group, the overall depressive symptoms of participating students aged 14-16 years in Hong Kong; (b) whether the effects were more significant among the-highsymptom students compared with the control participants; and (c) whether it had an enhancement effect on various the protective factors of depression. Despite considerable preparation and utilizing utilization of a structured programme based on the best evidence available in the literature to increase protective factors and reduce risk factors for adolescent depressive symptoms, we did not find the LPD programme to be effective in reducing rates of depressive symptoms among the participating students. This result applied to both the full sample and subset of students who reported higher levels of depressive symptoms at the pre-intervention first assessment.

As previously mentioned, universal school-based programmes tend to show no or low efficacy and effectiveness in reducing participating students' depressive symptoms at the posttest assessment. It is noteworthy that the existing universal programmes are heterogeneous in terms of length of the programme, research design, program leader, length of follow-up assessment and thus, it is too early to conclude whether universal school-based programmes are efficaciousy or effective in depression prevention. Thus, fFuture evaluation studies should put more research focus on the content and the designs of the programmes (Calear \& Christensen, $\underline{2010)}$.

These findings may inevitably lead to devaluation of the use of universal programmes in schools and more generally, Chinese society, relative to the use of selective or indicated programmes. Immediate devaluation of universal programmes in schools or Chinese societies may be too hasty a conclusion, since this programme was a pilot project with a relatively small 
sample size, a high attrition rate, and a short follow-up time frame. First of all, the overall level of the-depressive symptoms of the students appeared to be relatively low during the pretestpretest time point (mean item score equalling 0.56 for the control group and 0.77 for the subject group [ranging from 0 to 3]), perhaps suggesting that the depressive-depression levels of the students were much too low for a depression prevention programme to have display a significant effect. Secondly, the unexpectedly high attrition rate may also have led to insufficient statistical power to detect group differences. And tThirdly, we believe that the effectiveness of such programmes may not become apparent for-until longer period of - $\underline{\text { a longer period of time has }}$ passed, but because of limited funding prevented us from to conducting a longer term follow-up of our subjects, we were only able to conduct the pesttestpost-test evaluations right when the twelve-session programme finished. Fourthly, given the small sample size of the study and potential self-selection bias of the study, the findings of this study allow some generalizability but more extensive and rigorous study designs are needed. Fifthly, the findings of the study were primarily generated from self-report measurements which may raise concerns for a range-number of reasons including systematic response distortions, and the psychometric of questionnaire Formatted: English (U.K.) $\underline{\text { scales. }}$

In the absence of results to showing that the LDP had a statistically significant impact on levels of students' levels of depression, the importance of the study resides in the following three considerations: (a) an understanding as to why there was no effect; (b) an understanding of what else might have worked; and (c) a recommendation of steps that could be taken to improve the impact of future similar universal programmes.

\subsection{Why Was There no Effect?}


An effective trial for a school-based, universal programme for adolescent depression prevention requires a very large sample size to provide sufficient power for valid statistical analysis. Only four schools (two as the intervention group and two as the control group), however, participated in thise study and while the sample size was further reduced by a high attrition rate of the participating students. For confidentiality reasons, we first assigned students a pseudo number as an identifier during data collection, but the procedure was nallenging for the teachers to execute and students were often found to be copying the wrong numbers. Therefore, we subsequently replaced the pseudo number with date of birth as the identifier. Despite the more personalised nature of the new identifier, many students still wrongly filled in the date on their pestestpost-test questionnaires. Thus, some pestestpost-test questionnaires could not be matched with the pretestpre-test questionnaires. As a result, in addition to the small number of schools participating in the study, this-the inability to match the postest-test questionnaires might have adversely affected the statistical power of detecting group differences and restricted us from investigating additional possible attributes related to the outcomes.

Furthermore, schools are busy places with many teaching and learning agendas, and teachers have-not only have hing to teach but also have many administrative activities to attend to. This-Their crowded schedule was reflected in our considerable efforts to convince the potential and participating schools to maintain the fidelity of the programme. Unfortunately, some potential schools were unable to participate in the programme mainly because of its length, and although the participating schools tried their very best, some intervention sessions had to be reduced in length owing to unpredictable circumstances. These experiences highlighted some of the practical difficulties of implementing universal, mental-health-related programmes as part of a school curriculum in Hong Kong, where students' academic results are still regarded as the 
most significant, if not the only, achievement of students by schools, parents, and students. It is hoped that this situation may be improved by the recent local education reform, which is suggested to be student-focused and aims "to enable every person to attain all-round development in the domains of ethics, intellect, physique, social skills and aesthetics according to his/her own attributes so that he/she is capable of life-long learning, critical and exploratory thinking, innovating and adapting to change" (Education Bureau, 2007).

\subsection{What Works? Improvement of Help-Seeking Attitude and Self-Esteem}

While there was insufficient evidence to support a reduction in depressive symptoms, we did find positive and significant development in help-seeking attitudes and self-esteem for students who completed the programme. This finding is important as it is generally believed that if help-seeking behaviours among the distressed are enhanced, opportunities to intervene will open up (Seiffge-Krenke, 1993). In fact, most help-seeking studies using distressed adult and adolescent samples have generally supported the notion that adolescents rarely ask for informal (i.e., from friends or families) or formal (i.e., professional) help when distressed (Biddle, Gunnell, Sharp, \& Donovan, 2004). Whether this attitude development would transfer into action is yet to be determined so studies are needed to investigate whether an improved help-seeking attitude could lead to improvement in help-seeking behaviour.

An inverse relationship between self-esteem and risk of depression has long been studied. Recently, two large-scale studies in Hong Kong showed evidence of such relationship for adolescents at both secondary school and college age (Li, Chan, Chung, \& Chui, 2010; Song, Huang, Liu, Kwan, Zhang, \& Sham, 2008). A longitudinal study also shows that low self-esteem at adolescence is a significant predictor of depression at all times-throughout adulthood (Orth, Robins, Trzesniewski, Maes, \& Schmitt, 2009). This evidence eould be used to draw a 
eenclusionsuggests that enhancing self-esteem in adolescents; in Hong Kong, and perhaps universally, is an effective way of preventing the development of depressive symptoms in the short and long run. Effective self-esteem enhancement programmes such as the LPD could be implemented in schools as a prevention measure for depression or an enhancement of social and emotional well-being of young people in the wider community. It is noteworthy that we speculate that two possible reasons for the improvement of students' self-esteem is related to the interactive teaching and learning style of the LDP and our teachers' willingness to listen to the students in the programme. Indeed, we received positive comments from student take-home assignments stating that they felt their voices were heard and feelings were validated. Thus, the LPD had provided opportunities for them to share non-academic issues or concerns with eur

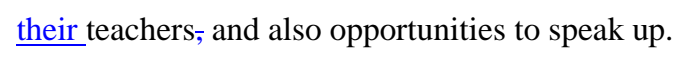

Subgroup analysis also showed evidence for positive and significant cognitivebehavioural development, namely, cognitive restructuring and support seeking, among the highsymptom students. These results were encouraging because cognitive restructuring skills are an essential component of interventions that adopt a cognitive behavioural model, and it is believed that mastering these skills has a sustainable effect on one's resilience to adverse situations (Hallfors et al., 2004). We must be cautious with this result, however, since it may be related to a number of extraneous factors, such as spurious effects, the small number of participating highsymptom students, and other pre-intervention and uncontrolled confounding factors, such as the academic exam-based secondary school track system and teaching medium of the schools.

\subsection{Steps for Future Improvement}

First, the current study adds to the growing debate on contrasting the efficacy and effectiveness of universal with selective and indicated programmes in preventing youth 
depression. This study is a replication (since most studies have been implemented in Western societies) as well as an extension (from a highly controlled environment to real-world use) of previous studies on universal school-based youth depression prevention programme. It is because of a number of limitations of the current study, that we failed to find statistically significant findings to support the effectiveness of such programmes for adolescent depression in Chinese societies. Future studies using larger sample sizes with extended time-series designs, permitting greater longitudinal analysis, are needed to add to the effectiveness, not just the efficacy, of such programmes. Moreover, future universal prevention programmes could consider using the onset of depressive symptoms or depression episodes rather than the level of depressive symptoms as the primary outcome, since logically the role of a prevention programme is to "prevent" something from happening, whereas the role of an intervention programme is to "reduce" something that has been happening. Adopting the same measuring principle or yardstick to evaluate the effectiveness of programmes serving different purposes appears unfair.

Second, it is noteworthy that during the programme, we identified a number of factors that may contribute to the complexity in sustaining the programme implementation after external resources are withdrawn (Han \& Weiss, 2005). Administrative support from the school leadership could be instrumental to effective implementation by identifying suitable personnel, allocating resources, and motivating and obtaining the commitment of the personnel to the program. Past research has also-concludesd that support from the school principal contributes to the success of school-based interventions (Kam, Greenberg, \& Walls, 2003).

Third, the Internet has become a very important and common platform for adolescents to express themselves, communicate with others, and obtain various kinds of information, including knowledge and skills related to health-physical and mental health. Internet-based mental health 
programmes will become much more common in the future, and researchers, practitioners, and policy makers need to plan strategically regarding how to develop, implement, and evaluate the effectiveness of these programmes. Furthermore, an Internet-based mental health programme would incur much lower costs, since it could serve a very large number of people at the same $\underline{\text { time. In addition, online platforms are very flexible in terms of time and place of learning. A }}$ $\underline{\text { recent review of Internet-based prevention and treatment programmes for anxiety and depression }}$ in children and adolescent suggesteds that internet-based programs are potentially effective for children and adolescents' anxiety and depression (Although only a few studies have been conducted to evaluate their effectiveness, they appear promising in reducing depressive symptoms and improving depression literacy (Griffiths \& Christensen, 2007Calear \& Christensen, 2010). More specifically, computerized cognitive-behavioural therapy appeartherapy appears to be an acceptablefeasible and effective intervention for young people at young age (Richardson, Stallard, \& Velleman, 2010). Furthermore, an Internet-based mental health programme would incur much lower costs, since it could serve a very large number of people at the same time. In addition, online platforms are very flexible in terms of time and place of learning.-We, thustherefore, suggest that further-future studies should-investigate Internetbased universal programmes as an alternative approach or adjunct component to traditional classroom-based universal programmes.

\section{Conclusion}

In summary, the present study did not find sufficient evidence to support the effectiveness of a school-based universal programme for preventing depression among adolescents. We believe, however, that the results drawn from this study are an important reminder of the very real and 
practical difficulties faced when implementing evidence-based practices generated from highly controlled settings to regular school settings.

Word Count: 5,1294,279 


\section{References}

Andrews, G., Szabo, M., \& Burns, J., 2002. Preventing major depression in young people. Br J Psychiatry. 181, 460-462.

Bagley, C., Bolitho, F., \& Bertrand L., 1997. Norms and construct validity of the Rosenberg selfesteem scale in Canadian high school populations: Implications for counselling. Can. J. Couns. 31, 82-92

Biddle, L., Gunnell, D., Sharp, D., \& Donovan, J.L., 2004. Factors influencing help seeking in mentally distressed young adults: A cross-sectional survey. Br J Gen Pract. 54, 248-253.

Bonate, P.L., 2000. Analysis of Pretest-posttest Designs. CRC Press, Boca Raton, FL.

Bursztein, C., \& Apter, A., 2009. Adolescent suicide. Curr Opin Psychiatr. 22, 1-6.

Calear, A.L. and Christensen, H., 2010, Review of Internet-based prevention and treatment

Formatted: Left programs for anxiety and depression in children and adolescents, Medical Journal of Australia, 192(11): S12.

Calear, A.L. and Christensen, H., 2010, Systematic review of school-based prevention and early intervention programs for depression, Journal of Adolescence, 33: 429-438

Cardemil, E.V., Reivich, K.J., Beevers, C.G., Seligman, M.E., \& James, J., 2007. The prevention of depressive symptoms in low-income, minority children: Two-year follow-up. Behav Res Ther. 45, 313-327.

Carver, C.S., 1997. You want to measure coping but your protocol's too long: Consider the Brief COPE. Int J Behav Med. 4, 92-100.

Carver, C.S., Scheier, M.F., \& Weintraub, J.K., 1989. Assessing coping strategies: A theoretically based approach. J Pers Soc Psychol. 56, 267-283. 
Cheng, S.T., \& Chan, A.C., 2007. Multiple pathways from stress to suicidality and the protective effect of social support in Hong Kong adolescents. Suicide Life Threat Behav. 37, 187196.

Chou, K.L., 2000. Assessing Chinese adolescents' social support: The multidimensional scale of perceived social support. Pers Indiv Differ, 28, 299-307.

Education Bureau, Government of Hong Kong Special Administrative Region. (2007). Education reform highlights.

http://www.edb.gov.hk/index.aspx?nodeID=88\&langno=1http://www.edb.gov.hk/index.a $\underline{\text { spx }}$ ?nodeID=88\&langno=1 (accessed at $15 \mathrm{Feb}, 2012)$ http://www.edb.gov.hkt

index.aspx?nodeID=88\&langno=1

Fischer, E.H., \& Farina, A., 1995. Attitudes toward seeking professional psychological help: A shortened form and considerations for research. J. Coll. Student Dev. 36, 368-373.

Garber, J., 2006. Depression in children and adolescents: Linking risk research and prevention. Am J Prev Med. 31(Suppl. 1), S104-S125.

Gladstone, T.R.G., \& Beardslee, W.R., 2009. The prevention of depression in children and adolescents: A review. Can J Psychiatry. 54, 212-221.

Griffiths, K.M., \& Christensen, H., 2007. Internet-based mental health programs: A powerful tool in the rural medical kit. Aust. J. Rural Health. 15, 81-87.

Hallfors, D.D., Waller, M.W., Ford, C.A., Halpern, C.T., Brodish, P.H., \& Iritani, B., 2004. Adolescent depression and suicide risk: Association with sex and drug behavior. Am J Prev Med. 27, 224-231.

Han, S.S., \& Weiss, B., 2005. Sustainability of teacher implementation of school-based mental health programs. J Abnorm Child Psychol. 33, 665-679. 
Hayes, R.J.D., 2009. Cluster randomised trials. Boca Raton, FL: CRC Press.

Kam, C., Greenberg, M.T., \& Walls, C.T., 2003. Examining the role of implementation quality in school-based prevention using the PATHS curriculum. Prev Sci. 4, 55-63.

Leung, P.W.L., Hung, S.F., Ho, T.P., Lee, C.C., Liu, W.S., Tang, C.P.,\& Kwong, S.L., 2008. Prevalence of DSM-IV disorders in Chinese adolescents and the effects of an impairment criterion: A pilot community study in Hong Kong. Eur Child Adolesc Psychiatry. 17, 452-461.

Li, W.H.C., Chan, P.S.L., Chung, O.K.J., \& Chui, M.L.M., 2010. Relationships among mental health, self-esteem and physical health in Chinese adolescents: An exploratory study. J Health Psychol. 15, 96-106.

Lovibond, S.H., \& Lovibond, P.F., 1995. Manual for the depression anxiety stress scales (2nd ed.). Sydney: Psychology Foundation of Australia.

Merry, S., McDowell, H., Hetrick, S., Bir, J., \& Muller, N., 2004. Psychological and/or educational interventions for the prevention of depression in children and adolescents. Cochrane Database Syst Rev. 1, CD003380.

Mezulis, A.H., Hyde, J.S., \& Abramson, L.Y., 2006. The developmental origins of cognitive vulnerability to depression: Temperament, parenting, and negative life events in childhood as contributors to negative cognitive style. Dev Psychol. 42, 1012-1025.

Mrazek, P.B., \& Haggerty, R.J._(Eds.), 1994. Reducing risks for mental disorders: Frontiers for preventive intervention research. National Academy Press, Washington, DC. 
Naylor, P. B., Cowie, H. A., Walters, S. J., Talamelli, L., \& Dawkins, J., 2009. Impact of a mental health teaching programme on adolescents. Brit J PsychiatBritish Journal of Psychiatry, 194(4), 365-370.

Offord, D.R., Kraemer, H.C., Kazdin, A.E., Jensen, P.S., \& Harrington, R., 1998. Lowering the burden of suffering from child psychiatric disorder: Trade-offs among clinical, targeted, and universal interventions. J Am Acad Child Adolesc Psychiatry. 37, 686-694.

Orth, U., Robins, R.W., Trzesniewski, K.H.,_Maes, J., \& Schmitt, M., 2009. Low self-esteem is a risk factor for depressive symptoms from young adulthood to old age. J Abnorm Psychol. $118,472-478$.

Robins, R.W., Hendin, H.M., \& Trzesniewski, K.H., 2001. Measuring global self-esteem: Construct validation of a single-item measure and the Rosenberg self-esteem scale. Pers Soc Psychol Bull. 27, 151-161.

Rogers, W.H., 1993. Regression standard errors in clustered samples. Stata Technical Bulletin, 13(19-23), 13.

Richardson, T.Richardson, T.Richardson, T., Stallard, P. and Velleman, S.Velleman, S.Velleman, S., 2010. Computerised cognitive behavioural therapy for the prevention and treatment of depression and anxiety in children and adolescents: a systematic review.Computerised cognitive behavioural therapy for the prevention and treatment of depression and anxiety in children and adolescents: a systematic review. Clin Child Fam Psychol Rev, 13 (3), pp. 275-290.

Seiffge-Krenke, I., 1993. Stress and coping in adolescence. Introduction. J Adolesc. 16, 227-233.
Formatted: Font: Not Italic Formatted: Font: Not Italic

Formatted: Polish

Formatted: Font color: Auto Formatted: Font color: Auto Formatted: Font color: Auto Formatted: Font color: Auto Formatted: Default Paragraph Font Formatted: Default Paragraph Font

Formatted: Indent: Left: $0 \mathrm{~cm}$, First line: $0 \mathrm{~cm}$ 
Shochet, I. M., Dadds, M. R., Holland, D., Whitefield, K., Harnett, P. H., \& Osgarby, S. M., 2001. The efficacy of a universal school-based program to prevent adolescent depression. J Clin Child Psycholłournal of Clinical Child Psychelogy, 30(3), 303-315.

Siu, A.M.H., \& Shek, D.T.L., 2005. The Chinese version of the social problem-solving inventory: Some initial results on reliability and validity. J Clin Psychol. 61, 347-360.

Song, Y., Huang, Y., Liu, D., Kwan, J.S.H., Zhang, F., Sham, P.C., Tang, S.W., 2008. Depression in college: Depressive symptoms and personality factors in Beijing and Hong Kong college freshmen. Compr Psychiatry. 49, 496-502.

Spence, S.H., \& Shortt, A.L., 2007. Research review: Can we justify the widespread dissemination of universal, school-based interventions for the prevention of depression among children and adolescents? J Child Psychol Psychiatry. 48, 526-542.

Taouk, M., Lovibond, P.F., \& Laube, R., 2001. Psychometric properties of a Chinese version of the 21-item Depression Anxiety Stress Scales (DASS21). Cumberland Hospital, Sydney, NSW.

Welbourne, J.L., Eggerth, D., Hartley, T.A., Andrew, M.E., \& Sanchez, F., 2007. Coping strategies in the workplace: Relationships with attributional style and job satisfaction. J Vocat Behav. 70, 312-325.

World Health Organization., 2005. Mental health atlas. Author, Geneva, GE.

Yeung, K.C.F., 1998. The dynamics of interparental conflict and adolescent's behavior problems. Doctoral dissertation, Hong Kong University.

Yu, D.L., \& Seligman, M.E.P., 2002. Preventing depressive symptoms in Chinese children. Prevention \& Treatment. 5, 1-39. 
Zimet, G.D., Dahlem, N.W., Zimet, S.G., \& Farley, G.K., 1988. The Multidimensional Scale of Perceived Social Support. J Pers Assess. 52, 30-41. 
${ }^{*}$ Acknowledgement

Conflict of Interest: There is no conflict of interest from any of the authors. 
Figure 1. Flow of student participants through the study

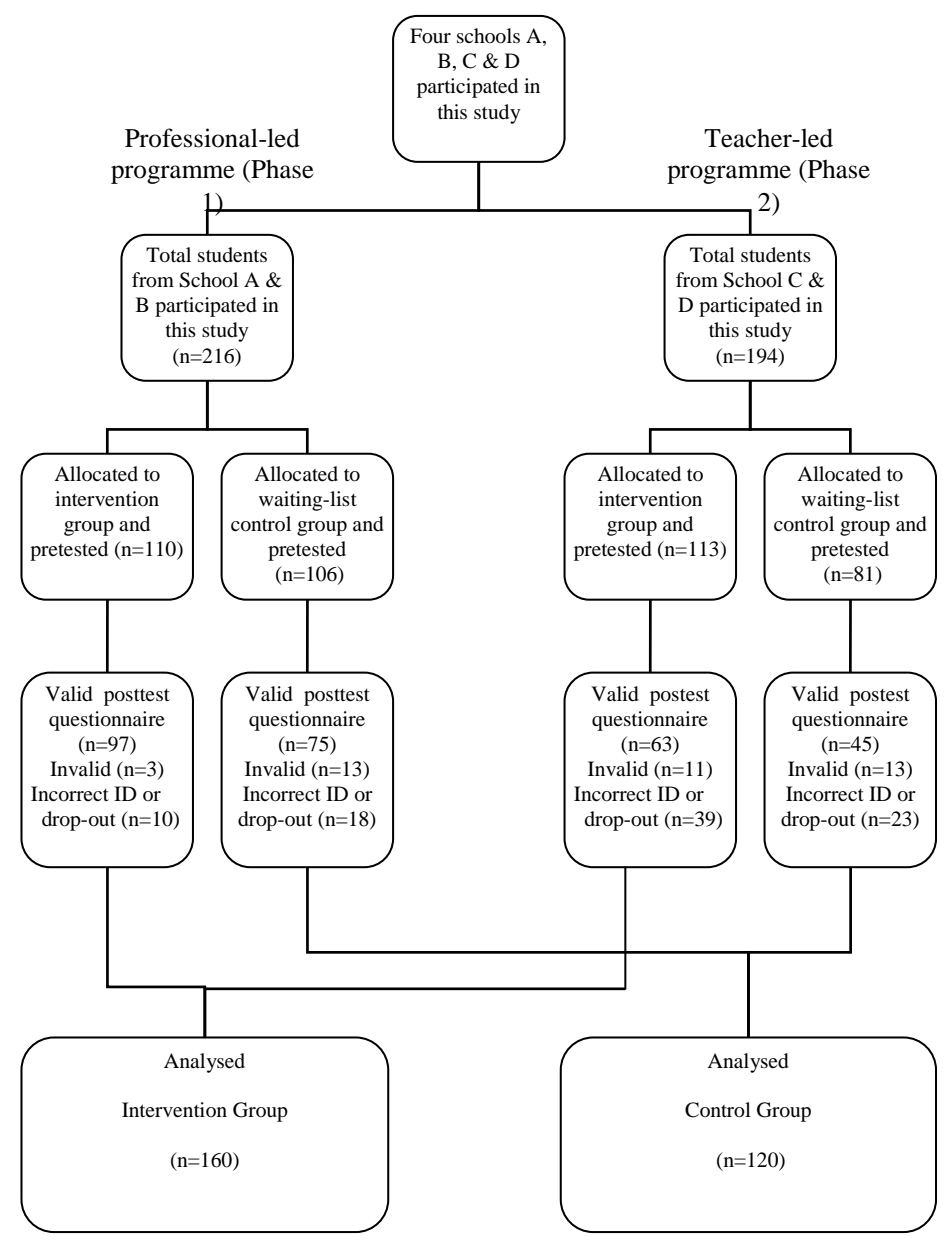


Table 1

Characteristics of the participants

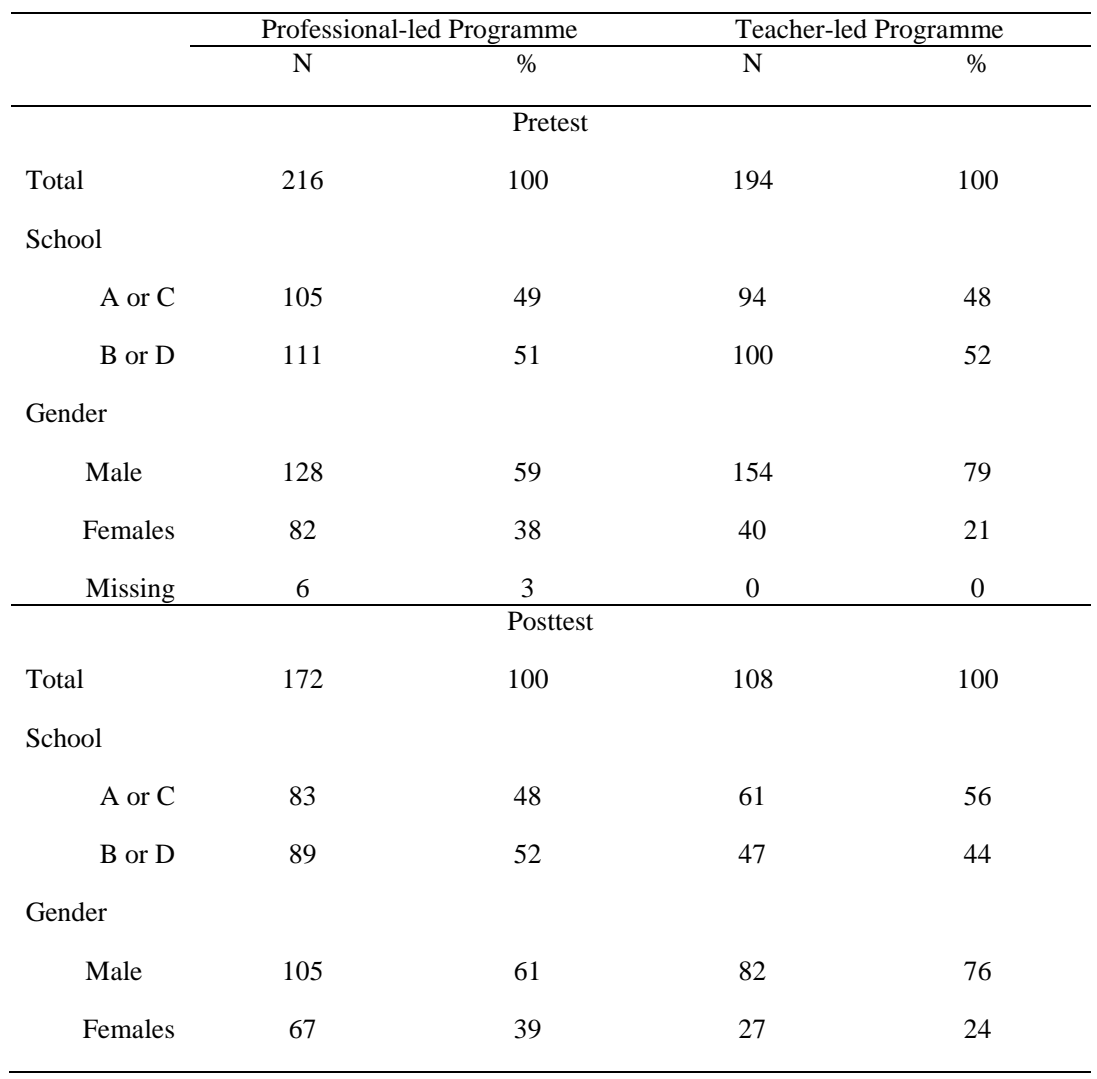




\section{Table 2}

Pre-test and post-test mean item scores (SD) and the test for intervention effect $\mathrm{X}$ mode of instruction, all samples

\begin{tabular}{|c|c|c|c|c|c|c|c|}
\hline & & \multicolumn{2}{|c|}{ Control } & \multicolumn{2}{|c|}{ Intervention } & \multirow{2}{*}{$\begin{array}{c}\beta \text { coefficient ( } \mathrm{p} \text { value) } \\
\text { - for Intervention effect X Mode of Instruction* }\end{array}$} & \multirow{2}{*}{$\begin{array}{l}\text { Item } \\
\text { score } \\
\text { range }\end{array}$} \\
\hline & & Pretest & Posttest & Pretest & Posttest & & \\
\hline \multicolumn{8}{|c|}{ Both professional-led and teacher-led intervention: intervention group $(n=160)$ and control group $(n=120)$} \\
\hline Depression & & $0.56(0.59)$ & $0.64(0.62)$ & $0.77(0.73)$ & $0.87(0.75)$ & $\underline{0.04(0.802)} \mathrm{ns}_{\mathrm{A}}$ & $0-3$ \\
\hline Stress & & $0.74(0.57)$ & $0.84(0.59)$ & $0.91(0.64)$ & $1.00(0.70)$ & $-0.09(0.632)$ & $0-3$ \\
\hline Help seeking & & $2.64(0.72)$ & $2.60(0.72)$ & $2.66(0.83)$ & $2.69(0.70)$ & $0.20(0.002)^{* *}$ & $1-4$ \\
\hline Self-esteem ${ }^{1}$ & & $2.07(0.53)$ & $1.99(0.51)$ & $2.19(0.54)$ & $2.19(0.52)$ & $-0.05(0.04) * *$ & $1-4$ \\
\hline \multirow{2}{*}{ Social Support } & Friends & $5.16(1.48)$ & $5.08(1.56)$ & $4.95(1.44)$ & $4.88(1.60)$ & $\underline{-0.012(0.907)}) \mathrm{Hs}_{\mathrm{L}}$ & $1-7$ \\
\hline & Family & $4.68(1.65)$ & $4.66(1.55)$ & $4.64(1.54)$ & $4.55(1.57)$ & $\underline{0.075(0.431)} \mathrm{ns}_{\underline{\imath}}$ & $1-7$ \\
\hline \multirow[t]{3}{*}{ Brief COPE } & Cognitive restructuring & $2.82(0.59)$ & $2.79(0.57)$ & $2.68(0.58)$ & $2.74(0.56)$ & $\underline{-0.086(0.086)} \mathrm{ns}_{\underline{\Lambda}}$ & $1-4$ \\
\hline & Support-seeking & $2.68(0.72)$ & $2.61(0.79)$ & $2.62(0.75)$ & $2.71(0.82)$ & $\underline{-0.112(0.142)}) \mathrm{ns}_{\mathrm{A}}$ & $1-4$ \\
\hline & Avoidance coping & $1.75(0.59)$ & $1.81(0.56)$ & $1.88(0.66)$ & $1.96(0.68)$ & $\underline{0.003(0.972)} \mathrm{ns}_{\mathrm{A}}$ & $1-4$ \\
\hline \multirow{2}{*}{$\begin{array}{l}\text { Problem } \\
\text { Solving }\end{array}$} & Constructive orientation & $2.05(0.86)$ & $2.07(0.81)$ & $1.95(0.81)$ & $2.06(0.76)$ & $\underline{0.007(0.951)} \mathrm{As}_{4}$ & $0-4$ \\
\hline & Inhibitive orientation & $1.38(0.74)$ & $1.38(0.74)$ & $1.42(0.78)$ & $1.65(0.83)$ & $-0.08(0.681) \mathrm{Hs}^{-}$ & $0-4$ \\
\hline
\end{tabular}

${ }^{1}$ Lower self-esteem score represents higher self-esteem.

*Regression of log-transformed posttest scores on the main effects of intervention and mode of instruction (professional-led/teacherled intervention) as well as their interaction, adjusted for log-transformed pretest score, gender, school and clustering effect of class. $\mathrm{P}$-value represents the significance level of the regression coefficient for the interaction effect (intervention $\mathrm{X}$ mode of instruction). |** $\mathrm{p}<0.05 \quad$ ns not statistically significant 
Table 3

Subgroup analysis for high-depressive symptoms-score samples: pre-test and post-test mean item scores (SD) and the test for intervention-by-subgroup effect

\begin{tabular}{|c|c|c|c|c|c|c|c|c|}
\hline & & \multicolumn{2}{|c|}{ Control } & \multicolumn{2}{|c|}{ Intervention } & \multirow{2}{*}{$\begin{array}{l}\beta \text { coefficient ( } \mathrm{p} \text { value) for } 3 \text {-way interaction } \\
\text { Intervention effect } X \text { Mode of Instruction X } \\
\text { High vs. Low depressive symptoms groups* }\end{array}$} & \multirow{2}{*}{$\begin{array}{l}\text { Item } \\
\text { score } \\
\text { range }\end{array}$} & \\
\hline & & Pretest & Posttest & Pretest & Posttest & & & \\
\hline \multicolumn{8}{|c|}{ Both Professional-led and teacher-led led intervention: intervention group $(\mathrm{n}=44)$ and control group $(\mathrm{n}=25)$} & \multirow[b]{2}{*}{ Formatted: Centered } \\
\hline \multicolumn{2}{|c|}{ Depression } & $1.53(0.36)$ & $0.86(0.53)$ & $1.80(0.48)$ & $1.28(0.74)$ & $\underline{0.523(0.287)} \mathrm{ns}$ & $0-3$ & \\
\hline \multicolumn{2}{|l|}{ Stress } & $1.37(0.47)$ & $0.99(0.52)$ & $1.66(0.48)$ & $1.39(0.71)$ & $\underline{-0.045(0.937) \mathrm{ms}}$ & $0-3$ & Formatted Table \\
\hline \multicolumn{2}{|l|}{ Help seeking } & $2.78(0.61)$ & $2.60(0.78)$ & $2.60(0.89)$ & $2.61(0.76)$ & $\underline{0.262(0.165)} \mathrm{ns}$ & $1-4$ & Formatted: Centered \\
\hline \multicolumn{2}{|l|}{ Self-esteem ${ }^{1}$} & $2.46(0.49)$ & $2.24(0.33)$ & $2.61(0.60)$ & $2.37(0.50)$ & $\underline{0.108(0.353)} \mathrm{ns}$ & $1-4$ & Formatted: Centered \\
\hline \multirow{3}{*}{ Social Support } & Friends & $4.60(1.13)$ & $4.18(1.63)$ & $4.75(1.54)$ & $4.40(1.72)$ & $\overline{0.170(0.575)} \mathrm{ns}$ & $1-7$ & Formatted: Centered \\
\hline & Family & $4.28(1.57)$ & $3.81(1.57)$ & $4.36(1.59)$ & $4.08(1.68)$ & $\underline{\underline{0.170(0.589) \mathrm{As}}}$ & $1-7$ & Formatted: Centered \\
\hline & & & & & & & $1-1$ & Formatted: Centered \\
\hline \multirow{3}{*}{ Brief COPE } & Cognitive restructuring & $2.59(0.33)$ & $2.66(0.48)$ & $2.71(0.56)$ & $2.64(0.57)$ & $0.24(0.03)^{* *}$ & $1-4$ & Formatted: Centered \\
\hline & Support-seeking & $2.53(0.61)$ & $2.34(0.70)$ & $2.65(0.67)$ & $2.52(0.85)$ & $0.48(0.02)^{* *}$ & $1-4$ & Formatted: Centered \\
\hline & Avoidance coping & $2.25(0.68)$ & $2.01(0.51)$ & $2.39(0.65)$ & $2.19(0.69)$ & $\underline{-0.044(0.731) \mathrm{ms}}$ & $1-4$ & Formatted: Centered \\
\hline \multirow{2}{*}{$\begin{array}{l}\text { Problem } \\
\text { Solving }\end{array}$} & Constructive orientation & $1.98(0.48)$ & $1.8(0.650)$ & $1.95(0.71)$ & $1.90(0.80)$ & $\underline{0.695(0.061) \mathrm{ns}}$ & $0-4$ & Formatted: Centered \\
\hline & Inhibitive orientation. & $1.95(0.66)$ & $1.57(0.72)$ & $1.98(0.77)$ & $1.94(0.78)$ & $\underline{0.304(0.222) \mathrm{ns}}$ & $0-4$ & Formatted: Centered \\
\hline
\end{tabular}

${ }^{1}$ Lower self-esteem score represents higher self-esteem.

*Regression of log-transformed posttest scores on the main effects of intervention, mode of instruction (professional-led/teacher-led intervention), and High vs. Low depressive symptoms groups, as well as their 2-way and 3-way interactions, adjusted for logtransformed pretest score, gender, school and clustering effect of class. P-value represents the significance level of the regression coefficient for the 3-way interactions (Intervention effect X Mode of Instruction X High vs. Low depressive symptoms groups).

| ** $\mathrm{p}<0.05 \quad$ ns not statistically significant 
Role of Funding Source: This study was funded by the Quality Education Fund, Education Bureau of Hong Kong SAR Government. 
${ }^{*}$ Conflict of Interest

Conflict of interest: None. 